\title{
Cermets: Down to Earth and Microstructure
}

Forty years ago an exciting new class of materials that researchers hoped would combine the best properties of ceramics and metals began to emerge from academic and industrial research laboratories. The new materials were called cermets.

The advent of jet aircraft inspired much of the early cermet work. The optimum operating temperature of a jet engine $\left(1800-2400^{\circ} \mathrm{F}\right)$ was above the practical limit of high temperature metal alloys in use at the time $\left(1500^{\circ} \mathrm{F}\right)$. An ideal material would combine the high temperature strength and oxidation resistance of ceramics and the ductility and toughness of metal alloys.

The semantics of this research area would never be crystal clear.

The new materials were variously called ceremetallics, ceramuls, ceramals, metalceramics, and ceremets before the community agreed with the suggestion of A.L. Berger, chief of the Supercharger Branch of the U.S. Air Force's Wright Field Power Plant Laboratory, that the new materials be termed simply "cermets."

Cermets were defined broadly in 1950 by John B. Campbell, associate editor of the trade journal Materials $\mathcal{E}$ Methods, as "refractory metallic compounds combined with metals and fabricated primarily by powder metallurgy methods." He listed three kinds - oxide-metal, boride-metal, and carbide-metal combinations - but wrote that "the latter are nothing more nor less than cemented carbides, an old and respected family hardly in need of a more glamorous title."

For a decade and a half or so from the mid 1940s through the 1950s, researchers made and tested an extensive variety of combinations of metals with ceramic oxides, carbides, and borides through techniques of slip casting, sintering, infiltration, and explosive forming. First on the scene was Carborundum's ceramic/metal mix called Durhy and Dug, the aluminairon material made during the World War II by German researchers to substitute for scarce high strength metal alloys. The German work was revealed in postwar Army intelligence reports.

"In the early days, the problem (of making a cermet turbine blade) was not looked upon as being particularly difficult, but merely a matter of a little time to find that combination,'" wrote J.R. Tinklepaugh and W.B. Crandall of Alfred University in the 1960 book they edited, Cermets .

Moreover, although test parts were expensive to make, observers were confident that if the other problems associated with cermet properties would be overcome, making the use of these materials in large quantities practical, mass machining techniques would also be perfected.
But, it was not to be. Various teams produced cermet turbine blades (also called buckets) that proved individually strong, but all fell prey to their inherently low impact strength. The blades would shatter when struck by any piece of debris passing through the rotor.

Pratt \& Whitney and the National Advisory Committee for Aeronautics (the predecessor to the National Aeronautics and Space Administration) had discouraging experiences with iron-alumina cermet blades.

When tested a few at a time as part of a full rotor composed mostly of standard metal blades, some cermet blades survived runs more than 100 hours long. Next, expensive experiments were conducted with two completely cermet-bladed rotors in which any weak or defective buckets were rejected. They lasted only a disheartening 3 and 12 hours in operation before selfdestructing. "Probably a small object chipped a small piece from one bucket and this in turn broke out a larger piece from the next blade, thus starting a chain reaction," wrote Andrew J. Meyer, Jr. and George C. Deutch of NASA in a chapter in Cermets

Increasing the metal binder to $80 \%$ showed some improvement in impact strength, but at the expense of high temperature rupture strength. Thickening the trailing edge of the blade helped, but affected the aerodynamics so much it gave intolerable engine performance.

"All cermets thus far have insufficient strength and all conventional bucket alloys appear to have adequate strength," concluded Meyer and Deutch.

Poor bonding between the metallic and ceramic phases and a lack of fundamental knowledge of the material were blamed for the brittle behavior of cermets.

"Far too little attention has been paid to (the microstructure) of cermets," wrote M. Humenik and T.J. Whalen of Ford in another Cermets chapter, "even though in alloy systems much of the improvement in the mechanical properties achieved during the last 30 years can be attributed to the study and control of microstructure."

Soon the hopes for cermets came down to earth.

J.W. Graham and W.F. Zimmerman of General Electric asked in the March 1958 issue of Metal Progress, "What's Happened to Cermets?" E. Glenny of the U.K. National Gas Turbine Establishment lamented the turbine failures in "Cermets: A Hope That Did Not Materialize," in the December 18, 1962 issue of Engineering.

While cermets have yet to be successful in attaining their original goal, high temperature blading for jet engine turbines, they have found applications as ideal materials in many niches where their acknowledged superiority in hardness, wear, and corrosion resistance are valuable. These include cutting tools, nuclear reactors, electronic equipment, and auto brakes.

More recently, reactive-metal cermets based on boron carbide have been studied with an eye toward lightweight, tough materials for ambient temperature applications such as armor. These efforts have been led by Russian researchers. G.V. Samsonov and A.P. Panasyuk began their efforts in the late 1960s. A U.S. effort started at University of California-Los Angeles with Ilhan A. Aksay, Alex J. Pyzik, and Daniel $C$. Halverson, who are now at the University of Washington, Dow Chemical, and Lawrence Livermore National Laboratory, respectively.

Halverson's latest results show that a wide range of mechanical properties can be produced with various heat treatments. Indeed, it is one realization of Humenik's and Whalen's plea for greater understanding of the cermet microstructure.

Just don't suggest trying to make high temperature cermet turbine blades.

M. ROSS

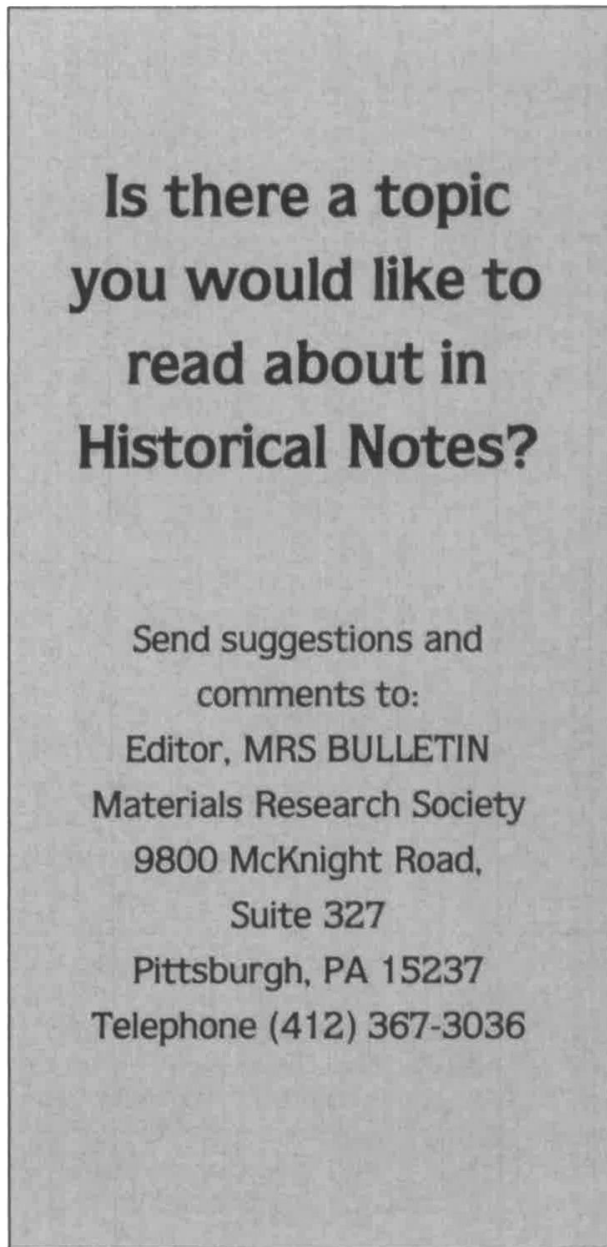

